\title{
Functional Interplay Between Two Xanthomonas oryzae pv. oryzae Secretion Systems in Modulating Virulence on Rice
}

\author{
Gopaljee Jha, Ramanan Rajeshwari, and Ramesh V. Sonti \\ Centre for Cellular and Molecular Biology, Uppal Road, Hyderabad-500 007, A.P., India
}

Submitted 14 June 2006. Accepted 8 August 2006.

\begin{abstract}
The type II (T2S) and type III (T3S) secretion systems are important for virulence of Xanthomonas oryzae pv. oryzae, causal agent of bacterial leaf blight of rice. The T3S of gramnegative bacterial plant pathogens has been shown to suppress host defense responses, including programmed cell death reactions, whereas the $\mathrm{T} 2 \mathrm{~S}$ is involved in secreting cellwall-degrading enzymes. Here, we show that a T3S-deficient $\left(\mathrm{T3S}^{-}\right)$mutant of $X$. oryzae pv. oryzae can induce a basal plant defense response seen as callose deposition, immunize rice against subsequent $X$. oryzae pv. oryzae infection, and cause cell-death-associated nuclear fragmentation. A T2S T3S $^{-}$double mutant exhibited a substantial reduction in the ability to evoke these responses. We purified two major effectors of the $X$. oryzae pv. oryzae T2S and characterized them to be a cellulase (ClsA) and a putative cellobiosidase (CbsA). The purified ClsA, CbsA, and lipase/esterase (LipA; a previously identified $\mathrm{T} 2 \mathrm{~S}$ effector) proteins induced rice defense responses that were suppressible by $X$. oryzae $\mathrm{pv}$. oryzae in a T3S-dependent manner. These defense responses also were inducible by the products of the action of these purified proteins on rice cell walls. We further show that a $\mathrm{CbsA}^{-}$mutant or a $\mathrm{ClsA}^{-} \mathrm{LipA}^{-}$double mutant are severely virulence deficient. These results indicate that the $X$. oryzae pv. oryzae T2S secretes important virulence factors, which induce innate rice defense responses that are suppressed by T3S effectors to enable successful infection.
\end{abstract}

Additional keywords: elicitors, host recognition, hydrolytic enzymes, pathogen-associated pattern molecules.

Plants and their bacterial pathogens have been coevolving during the millions of years of their coexistence. During this process, plants have evolved to mount defense responses upon detection of the presence of bacterial pathogens (Jones and Takemoto 2004; Nurnberger et al. 2004). One of the features of this defense response is a form of programmed cell death, known as the hypersensitive response (HR), that occurs at the site of infection (Goodman and Novacky 1994). The HR is postulated to restrict pathogen growth to the immediate vicinity of the infected region. A number of gram-negative plant-pathogenic bacteria have been shown to target effectors directly into the plant cell through a specialized protein secretion system

Corresponding author: Ramesh V. Sonti; Telephone: +91-40-27192577; Fax: +91-40- 27160591; E-mail: sonti@ccmb.res.in; rvsonti@yahoo.com

Nucleotide and amino acid sequence data are available at GenBank under accession numbers AY627914 and AY627915. called the type III protein secretion system (T3S) encoded by hypersensitive reaction and pathogenicity ( $h r p$ ) genes (Alfano and Collmer 1997; Chang et al. 2004). Recent research indicates that these effectors act as suppressors of defense responses, including programmed cell death (Abramovitch et al. 2003; Abramovitch and Martin 2004; Axtell and Staskawicz 2003; Bretz et al. 2003; Espinosa et al. 2003; Jamir et al. 2004; Mackey et al. 2003; Nomura et al. 2005) and localized basal resistance reactions that are induced by pathogen-associated pattern molecules (PAMPS) such as lipopolysaccharides (Keshavarzi et al. 2004) and flagellin (Felix et al. 1999; Li et al. 2005).

The plant cell wall is composed primarily of several polysaccharides such as cellulose, pectic substances, hemicelluloses like xylan, and so on, as well as lesser amounts of proteins, lipids, lignin, and other constituents (Esau 1965; McNeil et al. 1984). Cell-wall-degrading enzymes secreted by microbial pathogens have been shown to be elicitors of plant defense responses such as production of phytoalexins, fortification of cell walls by lignin deposition, oxidative burst, and so on (Darvill and Albersheim 1984; Ryan and Farmer 1991). The elicitor activity has been shown to lie in the polysaccharide degradation products (oligosaccharides) that are released by action of these enzymes. Cell-wall-degrading enzymes secreted by bacterial pathogens also have been shown to cause plant cell death (Braun and Rodrigues 1993). However, it is not clear whether this is due to the injury caused by the enzyme or due to a programmed cell death induced in response to this injury. Prior treatment with purified preparations of pectin-degrading enzymes produced by Erwinia carotovora pv. carotovora also have been shown to provide enhanced resistance against subsequent infection by the same pathogen (Palva et al. 1993). Therefore, the defense responses induced by the action of cell-wall-degrading enzymes and the oligosaccharide products resulting from their action should be a formidable challenge for successful infection by the pathogens. How might bacterial pathogens suppress this kind of cell-wall-based defense response?

Xanthomonas oryzae pv. oryzae causes bacterial leaf blight, a serious disease of rice. It has been demonstrated that a type II protein secretion system (T2S; also called general secretory pathway) and a T3S are important for virulence of $X$. oryzae pv. oryzae (Ray et al. 2000; Zhu et al. 2000). By characterizing defense responses that are induced by a T3S-deficient (T3S ${ }^{-}$) mutant and a $\mathrm{T}_{2} \mathrm{~S}^{-} \mathrm{T}_{3} \mathrm{~S}^{-}$double mutant as well as purified $\mathrm{T} 2 \mathrm{~S}$ effectors, we present evidence which indicates a functional interplay between these two secretion systems of $X$. oryzae pv. oryzae in modulation of rice defense responses and promotion of virulence. 


\section{RESULTS}

An $X$. oryzae pv. oryzae $\mathrm{T}^{-} \mathrm{S}^{-}$mutant induces rice defense responses in a T2S-dependent manner.

Rice leaves were infiltrated with $X$. oryzae pv. oryzae wild type (BXO43), T3S- (hrpB6:: bla; BXO2012) and $\mathrm{T}^{-} \mathrm{S}^{-} \mathrm{T} 3 \mathrm{~S}^{-}$ double mutant (hrpB6:: bla xpsF:: Tn10; BXO2013) (Table1). The hrpB6 gene encodes a component of the $X$. oryzae pv. oryzae T3S (Zhu et al. 2000) while the $x p s F$ gene encodes a component of the T2S (Ray et al. 2000). The number of callose deposits that are elicited by these strains was quantitated manually following epifluorescence microscopy. Callose deposition is considered to be a basal plant defense response (Bestwick et al. 1995; Brown et al. 1995). Higher amounts of callose deposition were detected in rice leaves that were infiltrated with BXO2012 (Fig. 1B) compared with those infiltrated with BXO43 (Fig. 1A) or BXO2013 (Fig. 1C; Table 2). Complementation of BXO2013 with a clone carrying the T2S gene cluster restored callose deposition to levels that are induced by BXO2012 (data not shown).

We then proceeded to determine whether the defense responses induced by a $\mathrm{T}_{3} \mathrm{~S}^{-}$mutant would provide resistance against subsequent $X$. oryzae pv. oryzae infection. Rice leaves were injected in the midvein with the BXO43, BXO2012, or $\mathrm{BXO} 2013$ strains of $X$. oryzae pv. oryzae, followed by inoculation 20 to $24 \mathrm{~h}$ later with $\mathrm{BXO} 43$. The leaves pretreated with BXO2012 strain (Fig. 2A-b) either were not exhibiting lesions or exhibited lesions of reduced length compared with leaves pretreated with BXO43 (Fig. 2A-a). On the other hand, compared with $\mathrm{BXO} 2012$, the BXO2013 strain exhibited a reduced ability to induce resistance (Fig. 2A-c; Table 3).
Programmed cell death reactions are associated with plant defense responses (Pennell and Lamb 1997). We assessed the ability of these $X$. oryzae pv. oryzae strains to induce cell death in rice roots by staining with propidium iodide (PI) and optical sectioning using a confocal microscope. Bright autoflouresence associated with the cell wall was observed in roots treated with BXO43; however, only a few cells took up PI, and the distribution of the stain indicated that the nucleus remained compact (Fig. 1D). The PI stain was taken up by all of the cells in rice roots treated with BXO2012, indicating that this strain induced extensive cell death (Fig. 1E). The PI staining material was no longer compact, indicating that the nucleus had undergone fragmentation. The BXO2013-treated roots did not take up any stain, indicating that this strain was unable to induce cell death (Fig. 1F).

\section{Characterization of T2S-secreted proteins of $X$. oryzae pv. oryzae.}

The proteins secreted by wild-type $X$. oryzae pv. oryzae (BXO43) into the extracellular medium were purified to apparent homogeneity from culture supernatants of peptone-sucrose (PS)-grown cultures by ammonium sulfate precipitation and passage through a cationic exchange MonoS column using FPLC (fast protein liquid chromatography). Passage through the column resulted in separation of three major fractions upon elution with 0 to $0.15 \mathrm{M} \mathrm{NaCl}$ gradient. The first, second, and third fractions resolved as single bands of approximately 48-, 39- and 59-kDa proteins, respectively, when analyzed with sodium dodecyl sulfate polyacrylamide gel electrophoresis (SDS-PAGE) (Fig. 3). The protein coming into the second peak previously has been characterized to be a lipase/esterase

Table 1. Plasmid and strain list

\begin{tabular}{|c|c|c|}
\hline Strain, plasmid, primer & Relevant characteristics $^{\mathrm{a}}$ & Reference, source \\
\hline \multicolumn{3}{|c|}{ Xanthomonas oryzae pv. oryzae strains } \\
\hline $\mathrm{BXO1}$ & Laboratory wild type; Indian isolate & Laboratory collection \\
\hline BXO43 & rif-2; $\mathrm{Rf}^{\mathrm{T}}$ derivative of $\mathrm{BXO} 1$ & Laboratory collection \\
\hline BXO802 & $\mathrm{Hrp}^{-}$, derivative of $\mathrm{BXO} 43$ & Ray et al. 2000 \\
\hline BXO805 & xps $F:: \mathrm{Tn} 10$ rif- $2 ; \mathrm{T}_{2} \mathrm{~S}^{-}$, derivative of $\mathrm{BXO} 43$ & Ray et al. 2000 \\
\hline BXO2001 & lipA1:: bla rif-2; $\mathrm{Lip}^{-}, \mathrm{Ap}^{\mathrm{r}}$ derivative of $\mathrm{BXO} 43$ & Rajeshwari et al. 2005 \\
\hline BXO2002 & clsAl:: bla rif- $2 ; \mathrm{Cls}^{-}, \mathrm{Ap}^{\mathrm{r}}$ derivative of $\mathrm{BXO} 43$ & This work \\
\hline BXO2003 & cbsAl:: gem rif- $2, \mathrm{Gm}^{\mathrm{r}}$ derivative of $\mathrm{BXO} 43$ & This work \\
\hline BXO2007 & clsA1::bla lipA1:: npt rif- $2 ; \mathrm{Lip}^{-}, \mathrm{Km}^{\mathrm{r}}$ derivative of $\mathrm{BXO} 2002$ & This work \\
\hline BXO2012 & hrpB6:: bla rif-2; $\mathrm{T} 3 \mathrm{~S} \mathrm{Hrp}^{-}, \mathrm{Ap}^{\mathrm{r}}$ derivative of $\mathrm{BXO} 43$ & This work \\
\hline BXO2013 & hrpB6:: bla xpsF :: Tn10 rif-2; $\mathrm{T}_{2} \mathrm{~S}^{-}, \mathrm{Tc}^{\mathrm{r}}$ derivative of $\mathrm{BXO} 2012$ & This work \\
\hline \multicolumn{3}{|c|}{ 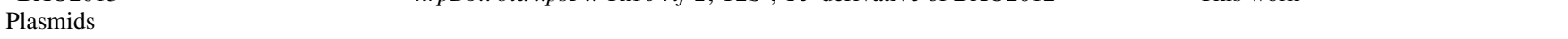 } \\
\hline pMOS-Blue & $A p^{r}$ & Amersham Pharmacia Biotech, U.K. \\
\hline pJQ200SK & sacB $\mathrm{Tra}^{-} \mathrm{Mob}^{+} \mathrm{Gm}^{\mathrm{r}}$ & Quandt and Hynes 1993 \\
\hline pET28b & $\mathrm{Km}^{\mathrm{r}}$ & Novagen \\
\hline pGJ1 & pMOS-Blue+ 308-bp PCR-amplified fragment of lipA gene of BXO43 & Rajeshwari et al. 2005 \\
\hline pGJ2 & pMOS-Blue+ 703-bp PCR-amplified fragment of $c l s A$ gene of BXO43 & This work \\
\hline pGJ3 & pMOS-Blue+ 520-bp PCR-amplified fragment of $c b s A$ gene of BXO43 & This work \\
\hline \multirow[t]{2}{*}{ pGJ4 } & pJQ200SK+ 520-bp fragment of $c b s A$ (from pGJ3) cloned into PstI and & \\
\hline & $\begin{array}{l}\text { BamHI site of pJQ200SK } \\
\text { pET28b + 308-bp fragment of lipA (from pGJ1) cloned into EcoRI and }\end{array}$ & This work \\
\hline pGJ7 & $\begin{array}{l}\text { HindIII site of pET28b } \\
\text { Hito }\end{array}$ & This work \\
\hline pGJ12 & pMOS-Blue+ 744-bp PCR-amplified fragment of $h r p B 6$ gene of BXO43 & This work \\
\hline \multicolumn{3}{|c|}{ Plo } \\
\hline $\mathrm{ClsF}$ & 5' TCAACGCCCGCggnatgtaygt 3' & This work \\
\hline ClsR & 5' GCGCACGGAGgtccartcrtc 3' & This work \\
\hline $\mathrm{CbsF}$ & $5^{\prime}$ GCCGGGCCGCGaytgycaygc 3' & This work \\
\hline CbsR & 5' CGGGCCGCCCCancertt 3' & This work \\
\hline $\mathrm{sCbsF}$ & 5' GCGAGCTACCACTGACGCA 3' & This work \\
\hline sCbsR & 5' GTTGTAGAGCGCTTCCGCA 3' & This work \\
\hline HrpB6F & 5' CGGGCCGAAGTGGTGGGCT 3' & This work \\
\hline HrpB6R & $5^{\prime}$ GATCGACCCGCTCTCTCCC $3^{\prime}$ & This work \\
\hline
\end{tabular}


(LipA) (Rajeshwari et al. 2005) which is encoded by the XOO0526 gene in the $X$. oryzae pv. oryzae genome (Lee et al 2005). These proteins were considered as T2S effectors because their secretion was severely affected (40- to 50-fold reduction compared with $\mathrm{BXO} 43$ ) in a $\mathrm{T}_{2} \mathrm{~S}^{-}$mutant strain (data not shown).

The SDS-PAGE-excised bands of the first and third fractions were subjected to tandem mass spectrometry (MS/MS) analysis which, in turn, yielded sequence tags. For fraction 1, the obtained sequence tags (TMPASIDYSRNADLQGLTSLQILD KVIAEEFNAR and FAGTHALLLGEFGGKYGE) were homologous to putative cellulases from $X$. axonopodis pv. citri (accession number AAM35501) and $X$. campestris pv. campestris (accession number AAM42791) (da Silva et al. 2002). Four sequence tags (VDNPFVGASGYVNPDYSK, DAALAQ, TEYL DVLASTLANPK, and SASGNDVNTYVNSG) were generated from fraction 3 . All four tags were homologous to putative 1,4-
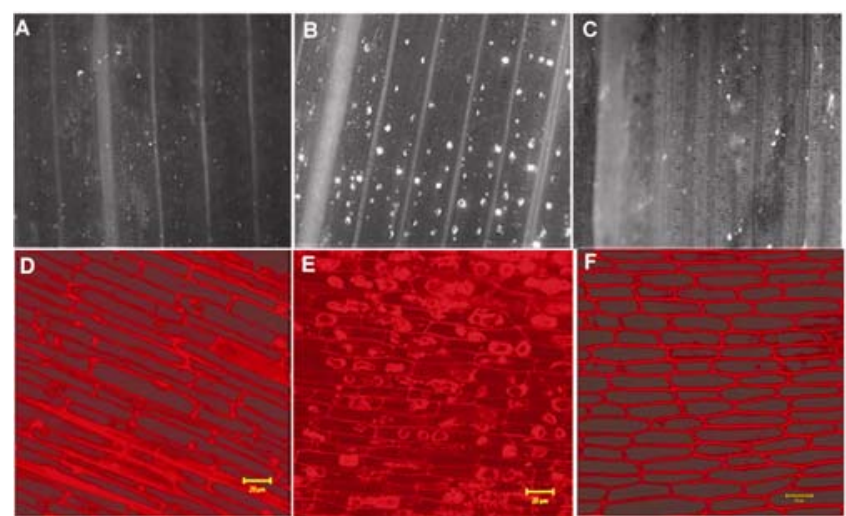

Fig. 1. Type III secretion system-deficient $\left(\mathrm{T}_{3} \mathrm{~S}^{-}\right)$Xanthomonas oryzae $\mathrm{pv}$. oryzae mutant induced callose deposition and cell death in a type II secretion system (T2S)-dependent manner. Rice leaves were infiltrated with $X$. oryzae pv. oryzae strains (BXO43, wild type; BXO2012, $\mathrm{T}^{-} \mathrm{S}^{-}$mutant; and BXO2013, T2 ${ }^{-}$T3S ${ }^{-}$double mutant) and examined under epifluorescence microscope after staining with aniline blue. White dots in these pictures are indicative of callose deposition. B, BXO2012 induces increased callose deposition compared with either A, BXO43 or C, BXO2013. Rice roots were treated with these $X$. oryzae pv. oryzae strains, stained with propidium iodide (PI), and examined under a confocal microscope. Treatment with either D, BXO43 or F, BXO2013 did not induce cell death (intake of PI), whereas treatment with $\mathbf{E}, \mathrm{BXO} 2012$ induced cell death and extensive nuclear fragmentation. Similar results were obtained in at least three independent experiments.

Table 2. A type III secretion system-deficient $\left(\mathrm{T}_{3} \mathrm{~S}^{-}\right) X$. oryzae pv. oryzae mutant induces callose deposition in rice leaves in a type II secretion system (T2S)-dependent manner

\begin{tabular}{lccc}
\hline & \multicolumn{3}{c}{ Mean number of callose deposits/0.6mm $\mathbf{a r e a}^{\mathbf{2}} \mathbf{S D}^{\mathbf{a}}$} \\
\cline { 2 - 4 } Experiment $^{\mathbf{b}}$ & BXO43 & BXO2012 & BXO2013 \\
\hline 1 & $15.4 \pm 16.3$ & $125.8 \pm 114.2$ & $14.1 \pm 11.9$ \\
2 & $18.8 \pm 19.6$ & $108.4 \pm 20.6$ & $11.5 \pm 15.2$ \\
3 & $70.3 \pm 61.3$ & $185.7 \pm 40.7$ & $82.6 \pm 55.0$ \\
4 & $57.0 \pm 21.0$ & $117.7 \pm 20.9$ & $46.3 \pm 22.0$ \\
5 & $42.5 \pm 45.7$ & $178.5 \pm 91.5^{\mathrm{c}}$ & $110.8 \pm 83.4^{\mathrm{c}}$ \\
\hline
\end{tabular}

${ }^{a}$ Mean and standard deviation (SD) were calculated for number of callose deposits from a leaf area of $0.60 \mathrm{~mm}^{2}$. Rice leaves were infiltrated with the $X$. oryzae pv. oryzae strains $\mathrm{BXO} 43$, wild type; $\mathrm{BXO} 2012$, T3S ${ }^{-}$ mutant; and BXO2013, $\mathrm{T}^{-} \mathrm{S}^{-} \mathrm{T}^{-} \mathrm{S}^{-}$double mutant, stained with aniline blue, and examined under epifluorescence microscope.

${ }^{\mathrm{b}}$ Data were collected from at least four leaves in each experiment and three different viewing areas from the infiltrated region of each leaf. Compared with treatment with BXO43 or BXO2013, the values obtained after treatment with BXO2012 were found to be significantly different at $P<0.05$ in all experiments except as indicated below.

c These two values are not significantly different at $P<0.05$ $\beta$-cellobiosidases from $X$. campestris pv. campestris (accession number AAM42804) and the citrus pathogen Xyllela fastidiosa (accession number AAF84076). No homologue of this protein was found in the Xanthomonas axonopodis pv. citri genome. The amino acids in the sequence tags (except for the underlined ones) were identical to the corresponding homologues.

The $X$. oryzae pv. oryzae protein resolved as fraction 1 in FPLC was confirmed to be a secreted cellulase (ClsA), based on positive assays for cellulase (endoglucanase) activity on PS agar (PSA) + carboxy methyl cellulose (CM-cellulose). Interestingly, the ClsA protein also showed a cellobiosidase (exoglucanase) activity when assayed with p-nitrophenyl cellobioside $(0.22 \mathrm{nmol} \mathrm{p}$-nitrophenol released $/ \mathrm{min} / \mu \mathrm{g})$ and methyl umbelliferyl cellobioside as substrates, indicating an exo- as well as endoglucanase activity for the enzyme. The purified protein resolved as fraction 3 exhibited only a limited cellobiosidase activity when assayed on p-nitrophenyl cellobioside $(0.04 \mathrm{nmol} \mathrm{p}$-nitrophenol released $/ \mathrm{min} / \mu \mathrm{g})$ or methyl umbelliferyl cellobioside as substrates. Because of the sequence homology and this limited enzyme activity, this protein is considered to be a putative $1,4-\beta$-cellobiosidase (CbsA) enzyme.

For genes encoding ClsA and CbsA, degenerate oligonucleotide primers were used to amplify and sequence intragenic fragments via polymerase chain reaction (PCR). Partial se-

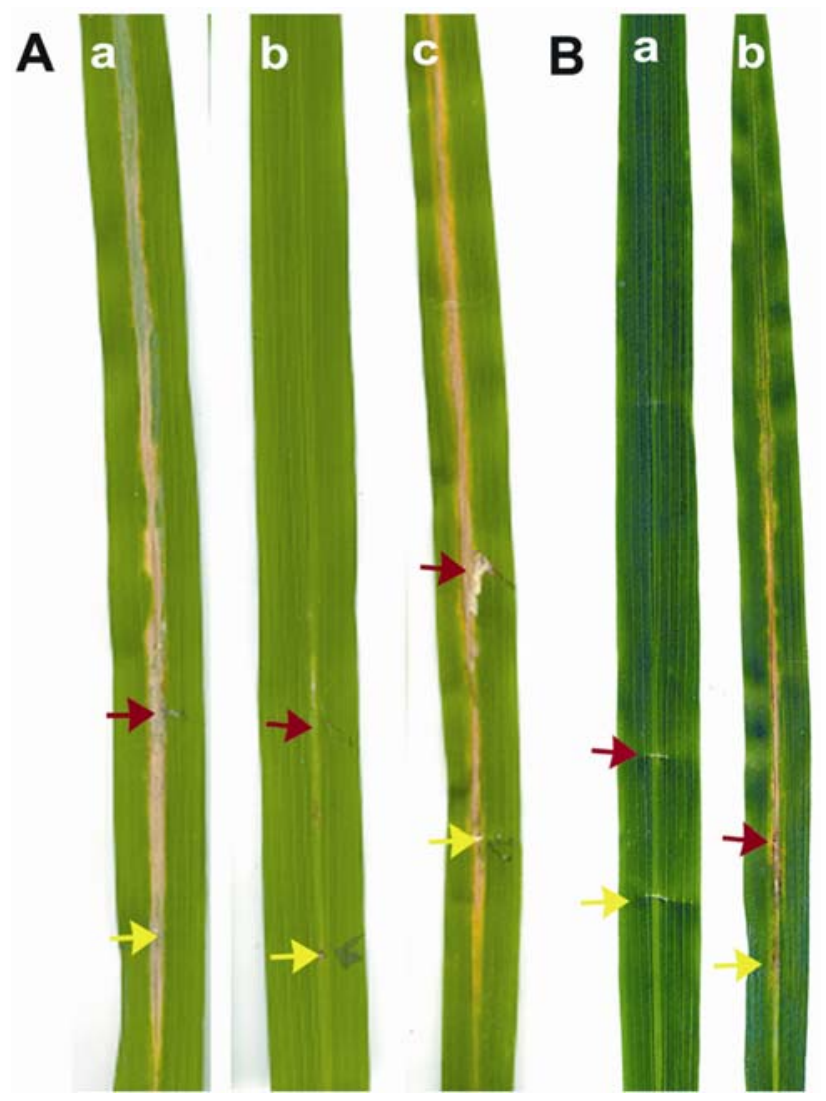

Fig. 2. Pretreatment of rice leaves with either A, type III secretion systemdeficient $\left(\mathrm{T}^{-} \mathrm{S}^{-}\right)$mutant or $\mathbf{B}$, purified cellulase (ClsA) induced resistance against subsequent Xanthomonas oryzae pv. oryzae infection. The midveinal regions of rice leaves were pretreated with one of the following: BXO43, wild type; BXO2012, T3S ${ }^{-}$mutant; and BXO2013, type II secretion system-deficient (T2 $\mathrm{S}^{-}$) $\mathrm{T}^{-} \mathrm{S}^{-}$double mutant; ClsA (4 to $5 \mu \mathrm{g} / \mathrm{ml}$ ); and buffer. After 20 to $24 \mathrm{~h}$, the BXO43 strain was inoculated 2 to $3 \mathrm{~cm}$ below the point of pretreatment. Disease lesions (discoloration of midveinal regions) formed in leaves pretreated with A-a, BXO43, A-c, BXO2013, and B-b, buffer, but were absent in leaves pretreated with A-b, BXO2012 or Ba, ClsA. Red arrows indicate the point of pretreatment whereas yellow arrows indicate the point of subsequent inoculation with BXO43. Similar results were obtained in three independent experiments. 
quences of the $c l s A$ (563 bp using ClsF and ClsR primers) and cbsA (517 bp using CbsF and CbsR primers) genes obtained in this study exhibited 100 and $96 \%$ identity, respectively, to the sequences of cellulase (XOO 4019) and cellobiosidase (XOO 4035) genes in the subsequently released genome sequence of the $X$. oryzae pv. oryzae strain KACC10331 (Lee et al. 2005). Single-gene disruption mutants of $c l s A$ (BXO2002) and $c b s A$ (BXO2003) and a lipA clsA double mutant (BXO2007) were generated as described in Materials and Methods. BXO2002 assayed negative for cellulase (endoglucanase) activity whereas BXO43 assayed positive for the activity. The BXO2007 mutant assayed negative for cellulase and lipase activities (data not shown). Mutations in the $\operatorname{cbs} A, c l s A$, and $\operatorname{lip} A$ genes also resulted in loss of the corresponding peaks after FPLC separation of culture supernatants.

The $c l s A(\mathrm{BXO} 2002)$ and $c b s A(\mathrm{BXO} 2003)$ and a lipA $c l s A$ double mutant (BXO2007) were assayed further for virulence on rice plants. The $\mathrm{BXO} 2003$ strain was drastically reduced for virulence, causing lesions whose length was approximately $8 \%$ of the lesions caused by BXO43. The $c l s A$-deficient $\left(c l s A^{-}\right)$ mutant was partially compromised for virulence, whereas the

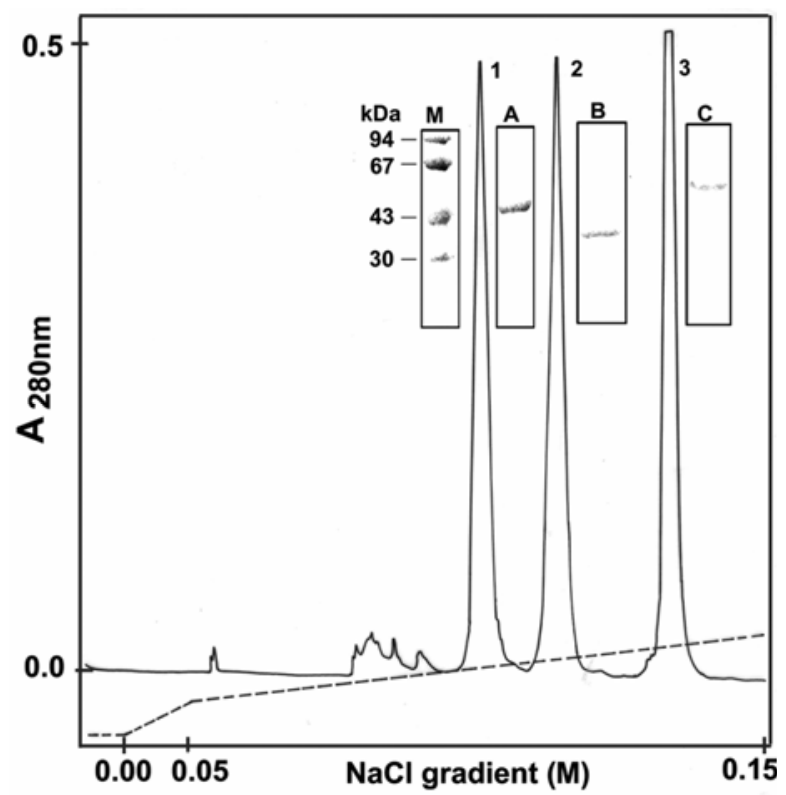

Fig. 3. Elution profile of Xanthomonas oryzae pv. oryzae type II secretion system-secreted proteins. The proteins were precipitated from culture supernatants with ammonium sulfate, desalted by dialysis, and loaded onto a MonoS column. The proteins were eluted with 0 to $0.15 \mathrm{M} \mathrm{NaCl}$ gradients (dashed line). Fractions showing absorbance at $280 \mathrm{~nm}$ were collected (solid line). The three major fractions depicted as 1,2 and 3 were cellulase (ClsA), lipase/esterase (LipA), and cellobiosidase (CbsA), respectively, whereas $\mathrm{A}, \mathrm{B}$, and $\mathrm{C}$ denote their corresponding silver-stained sodium dodecyl sulfate polyacrylamide gel electrophoresis profiles. $\mathbf{M}$ represents molecular mass standards in $\mathrm{kDa}$. lip $A^{-} c l s A^{-}$mutant was severely virulence deficient (Fig. 4). As reported earlier (Rajeshwari et al. 2005), the $\operatorname{lip} A^{-}$mutant (BXO2001) exhibited a partial reduction in virulence.

\section{Induction of rice defense responses by T2S effectors.}

The purified T2S effectors, at a concentration of 1 to 2 $\mu \mathrm{g} / \mathrm{ml}$, were infiltrated into rice leaves in order to assess their ability to induce callose deposition. Although there was some variability, it was clear that infiltration with T2S effectors induced a substantially higher amount of callose deposition compared with leaves infiltrated with buffer alone (Fig. 5A-a, buffer; A-b, ClsA; and A-c, CbsA; similar results were obtained for LipA) (Table 4).

Interestingly, at higher concentrations ( 4 to $5 \mu \mathrm{g} / \mathrm{ml}$ ), the $\mathrm{T} 2 \mathrm{~S}$ effectors induced browning of the infiltrated region and increased autofluorescence due to deposition of lignin-like compounds (Fig. 5B-c and B-d, ClsA; B-e and B-f, CbsA) whereas the control treatments (Fig. 5B-a and B-b) did not exhibit these effects. Similar results were obtained for LipA. The browning reaction and increased deposition of lignin-like substances is characteristic of HRs that are induced in rice leaves infiltrated with incompatible strains of $X$. oryzae pv. oryzae (Reimers and Leach 1991; Yang et al. 2000). Infiltration of commercially available cellulase and xylanase enzymes from Trichoderma spp. as well as a Bacillus lipase into rice leaves also induced similar responses (data not shown). Infiltration with either the heat-inactivated $\mathrm{T} 2 \mathrm{~S}$ effectors or corresponding FPLC fractions of culture supernatants of $c l s A^{-}$and lip $A^{-}$mutants that normally would contain ClsA and LipA proteins did not elicit either increased callose deposition or HRlike reactions (data not shown).

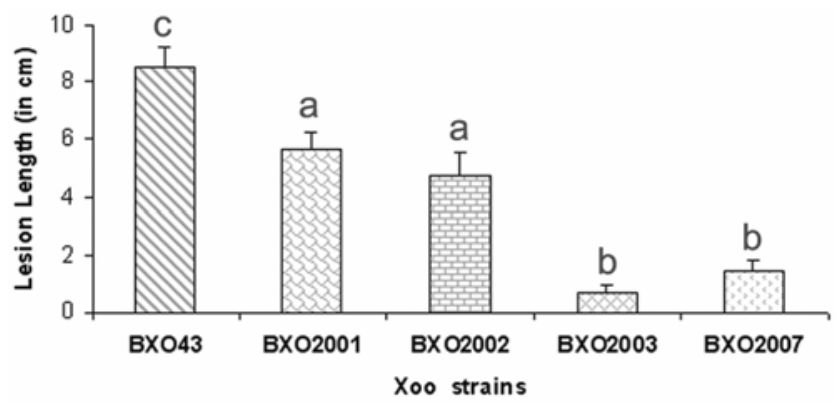

Fig. 4. Virulence deficiency associated with mutations in effectors of Xanthomonas oryzae pv. oryzae. BXO43 (wild type), BXO2001 (lipA1::bla), BXO2002 (clsA1::bla), BXO2003 (cbsA1::gem), and BXO2007 (lipA1::npt clsA1::bla) strains of $X$. oryzae pv. oryzae were inoculated on rice leaves and lesion lengths were measured 7 days post inoculation. Error bars indicate the standard deviation of readings from 10 inoculated leaves. Similar results were obtained in three independent experiments. A student's two-tailed $t$ test for independent means was performed in pairwise combinations for all the values. Values with the same letter are not significantly different at the $P<0.05$ level.

Table 3. Pretreatment with a type III secretion system-deficient $\left(\mathrm{T}^{-} \mathrm{S}^{-}\right)$Xanthomonas oryzae pv. oryzae mutant induces resistance in rice leaves in a type II secretion system (T2S)-dependent manner

\begin{tabular}{|c|c|c|c|c|c|c|c|c|}
\hline \multirow[b]{2}{*}{ Treatment $^{\mathrm{a}}$} & \multicolumn{2}{|c|}{ Experiment 1} & \multicolumn{2}{|c|}{ Experiment 2} & \multicolumn{2}{|c|}{ Experiment 3} & \multicolumn{2}{|c|}{ Experiment 4} \\
\hline & No. of leaves ${ }^{b}$ & Lesion $(\mathrm{cm})^{\mathrm{c}}$ & No. of leaves ${ }^{b}$ & Lesion $(\mathrm{cm})^{\mathrm{c}}$ & No. of leaves ${ }^{b}$ & Lesion $(\mathrm{cm})^{\mathrm{c}}$ & No. of leaves ${ }^{b}$ & Lesion $(\mathbf{c m})^{\mathrm{c}}$ \\
\hline $\mathrm{BXO} 43$ & $6 / 6$ & 20 & $6 / 6$ & 22 & $14 / 14$ & 21.2 & $11 / 11$ & $19.6^{\mathrm{d}}$ \\
\hline BXO2012 & $0 / 6$ & 0 & $1 / 6$ & 1 & $3 / 13$ & 0.6 & $5 / 12$ & 2.4 \\
\hline BXO2013 & $3 / 6$ & 7.5 & $4 / 5$ & 12 & $16 / 17$ & 9.1 & $15 / 15$ & $17.8^{\mathrm{d}}$ \\
\hline
\end{tabular}

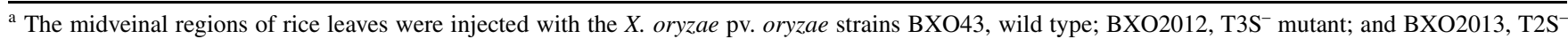

T3S ${ }^{-}$double mutant. Approximately 20 to $24 \mathrm{~h}$ later, the leaves were inoculated with BXO43, 2 to $3 \mathrm{~cm}$ below the point of initial injection.

${ }^{\mathrm{b}}$ Number of leaves showing disease lesion; lesions were observed 10 days after injection.

c Average lesion lengths obtained after treatment were found to significantly different at $P<0.05$ in all experiments, except as indicated below.

d These two values were not significantly different at $P<0.05$. 


\section{Prior treatment with $\mathbf{T} 2 \mathrm{~S}$ effectors induces resistance} to $X$. oryzae pv. oryzae.

Can the defense responses triggered by cellulase and other T2S effectors induce resistance to subsequent $X$. oryzae pv. oryzae infection? The $\mathrm{BXO} 43$ strain was able to cause lesions, as shown by browning of midvein and adjacent regions, in all leaves that had been preinjected with buffer (Fig. 2B-b) and was either unable to cause lesions or exhibited lesions of reduced lengths in leaves preinjected with the T2S effectors (Fig. 2B-a; Table 5).

Defense responses induced by $\mathrm{T} 2 \mathrm{~S}$ effectors are suppressed by $X$. oryzae pv. oryzae in a T3S-dependent manner.

In the above experiment, simultaneous injection with the T2S effectors and BXO43 did not affect lesion formation in any way (data not shown), indicating that BXO43 can suppress the ClsA-induced defense response when coinfiltrated. In order to assess the ability of wild-type $X$. oryzae pv. oryzae to suppress defense responses, rice leaves were coinfiltrated with BXO43 along with the T2S effectors. Coinfiltration of rice leaves with purified ClsA protein and the BXO43 strain resulted in suppression of the HR-like symptoms (Fig. 6A) and ligninlike autofluorescence (Fig. 6B) induced by ClsA. Coinfiltration with $\mathrm{T}^{-} \mathrm{S}^{-}$. oryzae pv. oryzae mutants (BXO2012 and BXO802) did not result in suppression of HR-like symptoms (Fig. 6C, data for BXO2012) and lignin-like autofluorescence (Fig. 6D, data for BXO2012). Similarly, coinfiltration with BXO43, but not BXO2012, resulted in inhibition of the HR- like responses and lignin autofluorescence that are induced in leaves by LipA and CbsA proteins (data not shown).

Rice roots were treated with the purified T2S effectors, stained with PI, and sectioned with a confocal microscope. The cells of rice roots treated with ClsA readily stained with PI and the nucleus was fragmented (Fig. 7B), whereas PI was excluded from the cells of buffer-treated roots (Fig. 7A). TUNEL assay staining of isolated rice root cap cells treated with T2S effectors indicated that the DNA was fragmented (data not shown). PI was not taken up in roots treated with

Table 4. Type II secretion system (T2S) effectors induce callose deposition in rice leaves

\begin{tabular}{lcccc}
\hline & \multicolumn{4}{c}{ Mean number of callose deposits/0.6mm } \\
\cline { 2 - 5 } Exp $^{\mathbf{b}}$ & Bufea $\pm \mathbf{S D}^{\mathbf{a}}$ \\
\cline { 2 - 5 } 1 & $37.1 \pm 20.0$ & $154.8 \pm 40.4$ & $140.6 \pm 52.5$ & $207.1 \pm 101.5$ \\
2 & $6.0 \pm 6.0$ & $30 \pm 16.8$ & $53.7 \pm 20.2$ & $50.7 \pm 13.9$ \\
3 & $17.4 \pm 13.4$ & $82.0 \pm 52.3$ & $47.9 \pm 51.0$ & $127.2 \pm 12.4$ \\
4 & $21.7 \pm 16.5$ & $326.1 \pm 87.3$ & $266.6 \pm 58.1$ & $279.4 \pm 87.3$ \\
\hline
\end{tabular}

${ }^{a}$ Rice leaves were infiltrated with either buffer or diluted concentrations of T2S effectors, stained with aniline blue, and examined under epifluorescence microscope. Mean and standard deviation were calculated for number of callose deposits from a leaf area of $0.60 \mathrm{~mm}^{2}$.

${ }^{b}$ Data were collected from at least four leaves in each experiment (Exp) and three different viewing areas of the infiltrated region in each leaf. Compared with treatment with buffer, the values obtained after treatment with T2S effectors were found to be significantly different at $P<0.05$ in all experiments.
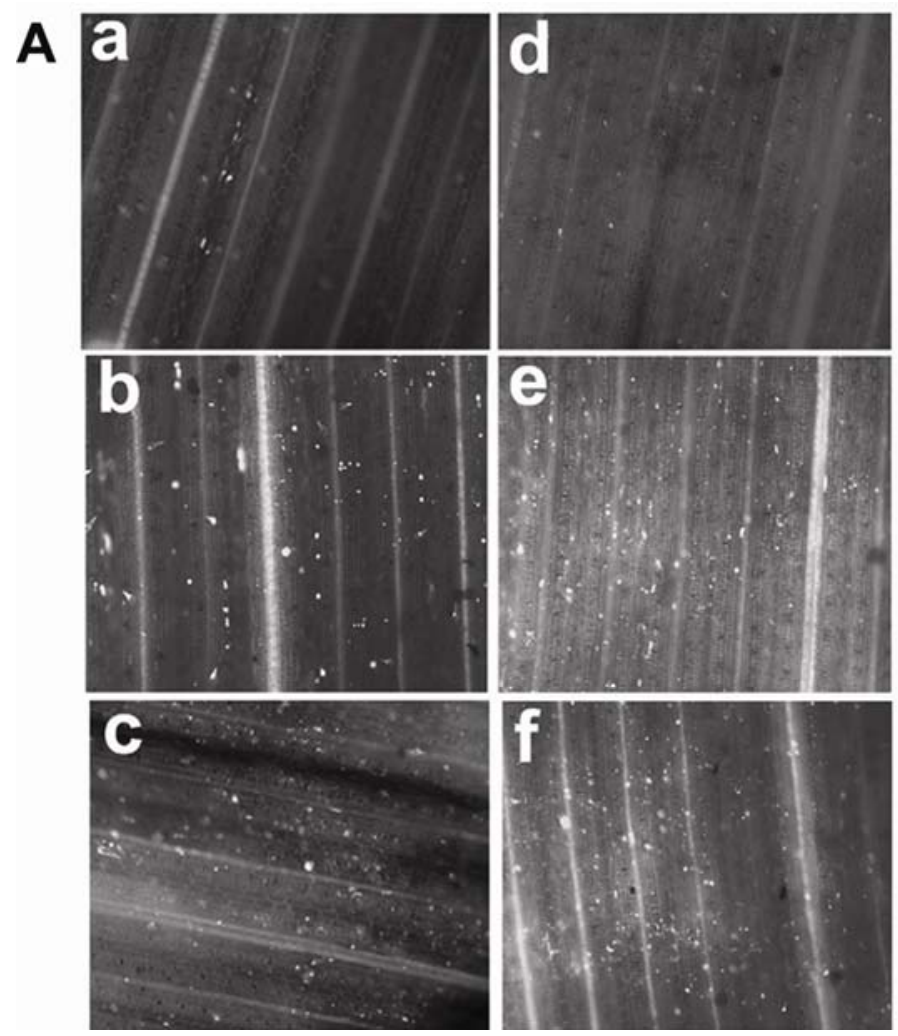
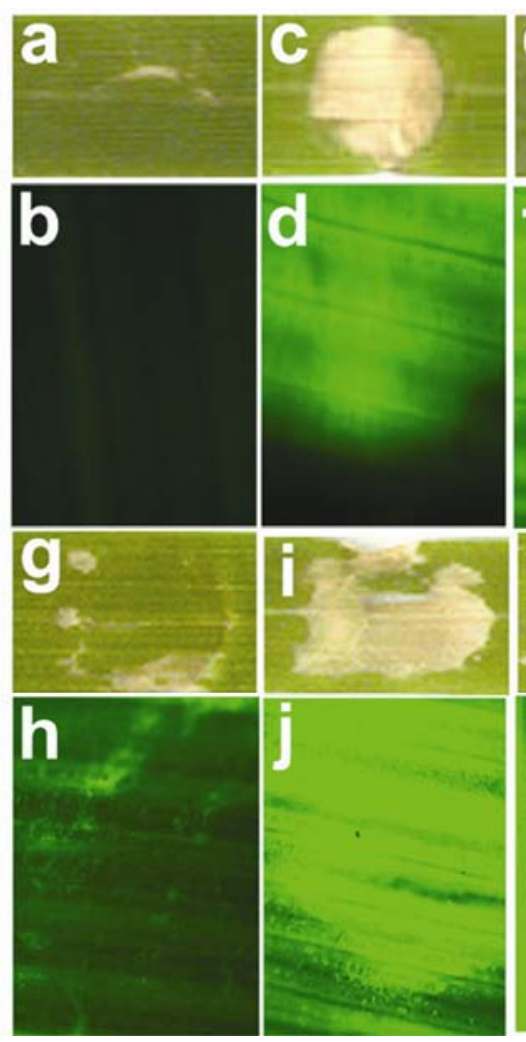
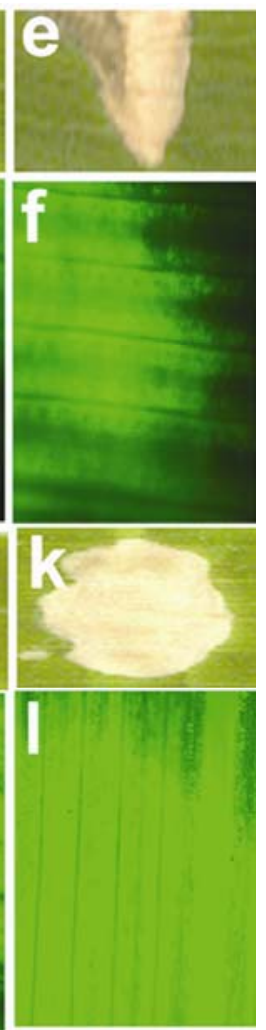

Fig. 5. Type II secretion system (T2S) effectors and the soluble elicitors released by their action induced rice defense responses. A, Rice leaves were examined under epifluorescence microscope after infiltration with diluted concentrations of the following: b, cellulase (ClsA), c, cellobiosidase (CbsA), a, buffer, or soluble elicitors released by treatment of crude cell wall preparations with e, ClsA, f, CbsA, and d, buffer. Staining was with aniline blue. White dots in these pictures are indicative of callose deposition. B, Adaxial surfaces of 10-day-old rice leaves were infiltrated with the following: purified T2S effectors alone and soluble elicitors released by treatment of crude cell wall preparations with ClsA. c and d, Hypersensitive response (HR)-like symptoms and increased lignin-like autofluorescence on leaves infiltrated with $\mathrm{ClsA}$; e and $\mathbf{f}$, similar responses induced by CbsA. Infiltration with buffer alone did not induce $\mathbf{a}$, HR-like symptoms or $\mathbf{b}$, increased autofluorescence. $\mathbf{i}$ and $\mathbf{k}, \mathrm{HR}$, and $\mathbf{j}$ and $\mathbf{l}$, lignin-like autofluoresence induced in leaves infiltrated with soluble elicitors released by treatment of crude cell wall preparations with ClsA and CbsA, respectively. $\mathbf{g}$ and $\mathbf{h}$, Corresponding treatment with supernatants from crude cell wall preparations treated with buffer alone. Similar results were obtained in three independent experiments. 
either heat-inactivated enzymes or the fraction from BXO2002 (ClsA ${ }^{-}$mutant) or BXO2001 (LipA ${ }^{-}$mutant) that normally would be expected to have the corresponding enzyme. Pretreatment with BXO43 suppressed ClsA-induced nuclear fragmentation in cells of rice roots (Fig. 7C). Although some of the cells took up PI, the nucleus was not fragmented. T3S mutants of $X$. oryzae pv. oryzae (BXO2012 and BXO802) were unable to inhibit ClsA-induced nuclear fragmentation (Fig. 7D, data for BXO2012). Similarly, pretreatment with BXO43, but not BXO2012, resulted in inhibition of nuclear fragmentation induced by LipA and CbsA.

\section{Soluble elicitors of defense responses are released through the action of T2S effectors.}

Crude preparations of rice cell walls were treated with the purified T2S effectors ( 4 to $5 \mu \mathrm{g} / \mathrm{ml}$ ). After heat inactivation of the enzyme, the supernatants (soluble elicitors) were collected, diluted four times in buffer, and infiltrated into rice leaves. The supernatants from rice cell wall preparations that had been
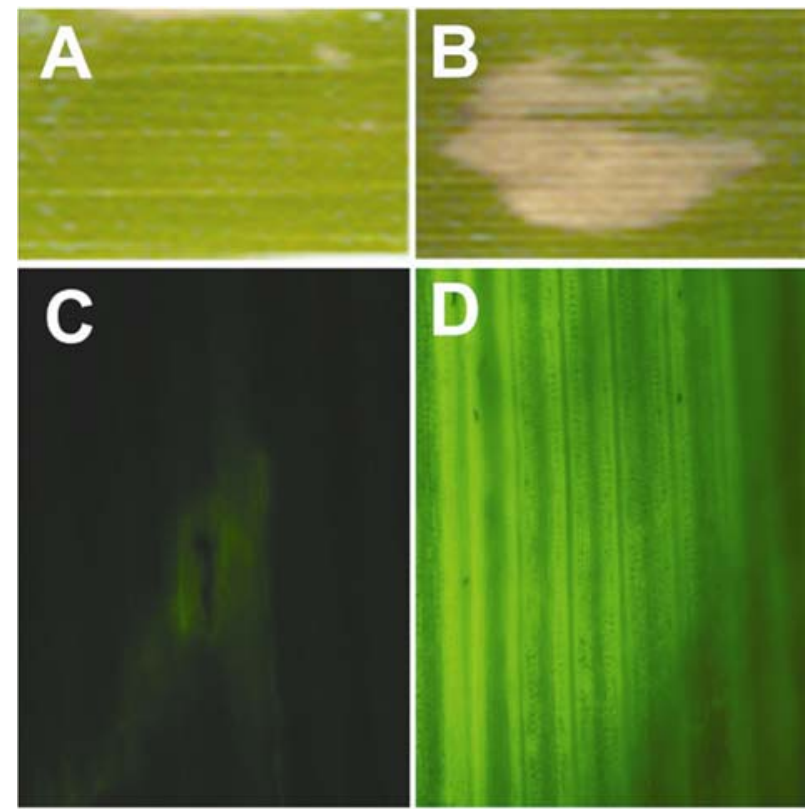

Fig. 6. Cellulase (ClsA)-induced hypersensitive response (HR) was suppressed by wild-type Xanthomonas oryzae pv. oryzae in a type III secretion system (T3S)-dependent manner. Adaxial surfaces of 10-day-old rice leaves were infiltrated with purified ClsA along with either BXO43 (wild type) or BXO2012 (type III secretion system-deficient mutant). Co-inoculation with BXO43 inhibited the $\mathbf{A}$, HR-like symptoms and $\mathbf{C}$, lignin-like autofluorescence that were induced by ClsA. Co-inoculation with BXO2012 failed to inhibit the B, HR-like symptoms and D, increased lignin autofluorescence that were induced by ClsA. Similar results were obtained in three independent experiments. treated with buffer alone (Fig. 5A-d) induced substantially lesser amounts of callose deposition compared with cell wall preparations that were treated with purified T2S effectors. The data for cell wall preparations that had been treated with ClsA (Fig. 5A-e) or CbsA (Fig. 5A-f) are provided; however, similar results were obtained with LipA. When rice leaves were infiltrated with the undiluted soluble elicitors, HR-like browning reaction and increased lignin-like autofluorescence were observed at the zone of infiltration (Fig. 5B-I, B-j, B-k, and B-1). The supernatants from rice cell wall preparations that had been treated with buffer alone did not induce such HR-like responses (Fig. 5B-g and B-h). These results indicate that the defense responses induced by $X$. oryzae pv. oryzae $\mathrm{T} 2 \mathrm{~S}$ effectors are due to elicitors released by their action on rice cell walls and not due to direct recognition of the enzymes. This is in contrast to the fungal xylanases, wherein a plant receptor has been shown to bind the enzyme leading to induction of defense responses (Ron and Avni 2004).
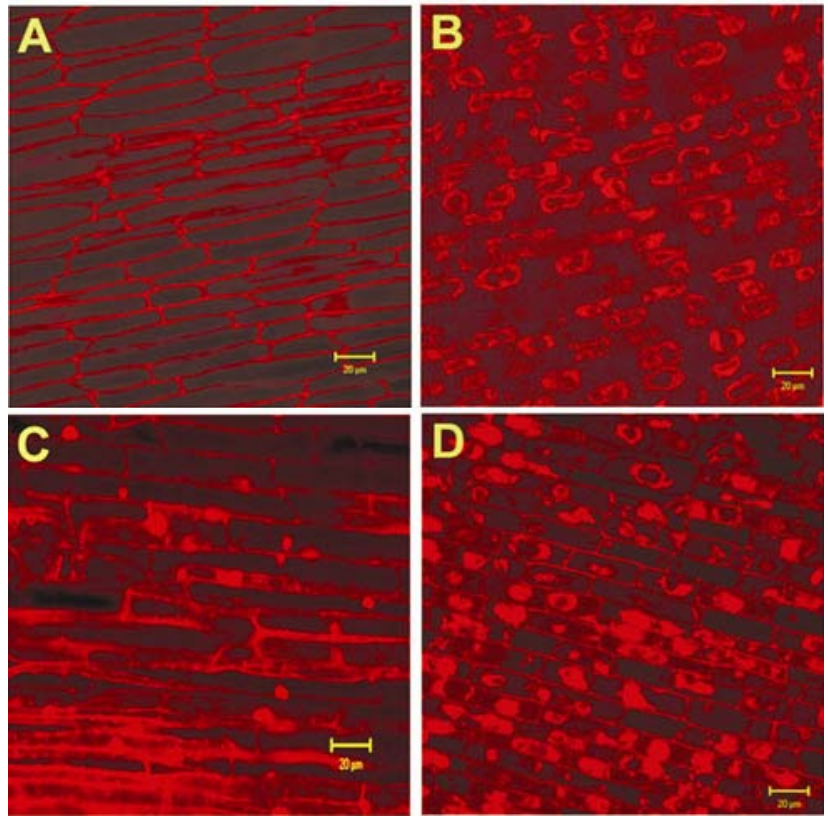

Fig. 7. Cellulase (ClsA)-induced cell death in rice roots was suppressed by wild-type Xanthomonas oryzae pv. oryzae in a type III secretion system (T3S)-dependent manner. Roots were isolated from rice seedlings, treated with the ClsA protein, stained with propidium iodide (PI), and examined under a confocal microscope. A, Control buffer-treated roots exhibited a prominent cell wall associated autofluorescence but no internalization of PI. B, Cell death and a characteristic ring like pattern of PI staining indicative of nuclear fragmentation were observed in ClsA-treated root cells. Prior inoculation with C, BXO43-wild type but not D, the BXO2012 type III secretion system-deficient mutant inhibited nuclear fragmentation. Similar results were obtained in at least three independent experiments.

Table 5. Pretreatment with type II secretion system (T2S) effectors induces resistance to subsequent $X$. oryzae pv. oryzae infection

\begin{tabular}{|c|c|c|c|c|c|c|c|c|}
\hline \multirow[b]{2}{*}{ Treatment $^{\mathrm{a}}$} & \multicolumn{2}{|c|}{ Experiment 1} & \multicolumn{2}{|c|}{ Experiment 2} & \multicolumn{2}{|c|}{ Experiment 3} & \multicolumn{2}{|c|}{ Experiment 4} \\
\hline & No. of leaves ${ }^{b}$ & Lesion $(\mathrm{cm})^{\mathrm{c}}$ & No. of leaves ${ }^{b}$ & Lesion $(\mathrm{cm})^{\mathrm{c}}$ & No. of leaves ${ }^{b}$ & Lesion $(\mathrm{cm})^{\mathrm{c}}$ & No. of leaves ${ }^{b}$ & Lesion $(\mathrm{cm})^{\mathrm{c}}$ \\
\hline Buffer & $5 / 5$ & 14 & $5 / 5$ & 21 & $5 / 5$ & 20 & $5 / 5$ & 18 \\
\hline ClsA & $0 / 5$ & 0 & $2 / 5$ & 1.6 & $2 / 5$ & 3 & $1 / 5$ & 0.6 \\
\hline LipA & $2 / 5$ & 4 & $3 / 5$ & 5.2 & $1 / 6$ & 0.6 & $3 / 6$ & 4.7 \\
\hline CbsA & $1 / 5$ & 1.6 & $3 / 5$ & 3.8 & $1 / 6$ & 0.3 & $3 / 6$ & 2.8 \\
\hline
\end{tabular}

a The midveinal regions of rice leaves were injected with the following: buffer, ClsA, CbsA or LipA. Approximately 20-24hr later, the leaves were inoculated with wild type $X$. oryzae pv. oryzae, $2-3 \mathrm{~cm}$ below the point of initial injection.

${ }^{\mathrm{b}}$ Number of leaves showing disease lesions; lesions were observed 10 days after injection.

c Average lesion length. Compared with treatment with buffer-treated leaves, the average lesion length obtained after treatment with T2S effectors were found to be significantly different at $P<0.05$ in all experiments. 


\section{DISCUSSION}

In this study, we demonstrate that a $\mathrm{T}^{-} \mathrm{S}^{-} X$. oryzae $\mathrm{pv}$. oryzae mutant (BXO2012) induces basal defense responses in rice leaves that are evident as callose deposition and resistance against subsequent infection by wild-type $X$. oryzae pv. oryzae. $\mathrm{Hrp}^{-}$mutants of several plant-pathogenic bacteria have been shown to induce callose deposition (Bestwick et al. 1995; Brown et al. 1995; Hauck et al. 2003; Jacobek and Lindgren 1993). Although purified bacterial elicitors such as lipopolysaccharide (LPS) and flagellin have been shown to be inducers of callose deposition (Keshavarzi et al. 2004; Kim et al. 2005), the extent by which they contribute to elicitation of defense responses by the $\mathrm{T}^{-} \mathrm{S}^{-}$mutant is not clear. We demonstrate that an $X$. oryzae pv. oryzae type II and type III secretion system double mutant $\left(\mathrm{T}_{2} \mathrm{~S}^{-} \mathrm{T} 3 \mathrm{~S}^{-}\right)$is defective in elicitation of callose deposition and induced resistance, indicating that the rice defense responses that are provoked by the $\mathrm{T}_{3} \mathrm{~S}^{-}$mutant are due mostly to action of the T2S.

The T2S of plant-pathogenic bacteria is known to secrete hydrolytic enzymes that are involved in degradation of plant cell walls (Jha et al. 2005). The $\mathrm{T}^{2} \mathrm{~S}^{-} X$. oryzae pv. oryzae mutants are severely virulence deficient (Ray et al. 2000). Mutation in the $c b s A$ gene leads to a severe virulence deficiency. A transposon insertion in a gene (XOO4036) which is immediately downstream of $c b s A$ does not lead to virulence deficiency (G. Jha and R. V. Sonti, unpublished data), indicating that the virulence deficiency associated with the mutation in $c b s A$ is not due to a polar effect on the downstream gene. Single mutations in the $\operatorname{cls} A$ gene and the $\operatorname{lip} A$ gene cause only a partial loss of virulence. A lipA clsA double mutant exhibits a substantial reduction in virulence compared with either of the single mutants, suggesting that there is functional redundancy with regard to the role of these two genes in virulence. It is possible that LipA acts on a lipidic component of rice cell walls and the loss of either this activity or ClsA activity has only a slight effect on virulence, whereas loss of both activities (in the double mutant) must somehow compromise virulence. The clsA1::bla and the lipA $1::$ blalnpt insertion was constructed in such a manner that the lacZ promoter of the plasmid is in the correct orientation to transcribe downstream open reading frames and minimize polar effects. Overall, these results, and those reported earlier (Rajeshwari et al. 2005), indicate that ClsA, CbsA, and LipA are important for $X$. oryzae pv. oryzae virulence. It is not clear why a mutation in the $c b s A$ gene has a much more severe effect on virulence than mutations in either the $c l s A$ or the lipA genes. One possible reason might lie in the observation that only one gene $(c b s A)$ has been annotated to encode a putative cellobiosidase, whereas there are several genes that have been annotated to encode putative cellulases and lipases in the $X$. oryzae pv. oryzae genome (Lee et al. 2005).

Paradoxically, purified T2S-secreted proteins induce potent defense responses. It appears that the callose deposition and HR-like reactions that are induced by $\mathrm{T} 2 \mathrm{~S}$-secreted proteins are due to soluble elicitors that are released by the action of these enzymes on rice cell walls. Wild-type $X$. oryzae pv. oryzae can suppress, in a T3S-dependent manner, the various responses induced by T2S effectors. Suppression of these defense responses is essential for infection to proceed. The results presented here demonstrate, for the first time, a functional interplay between the bacterial $\mathrm{T} 2 \mathrm{~S}$ and $\mathrm{T} 3 \mathrm{~S}$ in modulating rice defense responses and promoting disease.

What is the role of individual T2S-secreted proteins in eliciting defense responses during infection? The $X$. oryzae pv. oryzae genome is predicted to encode seven cellulases, four xylanases, and two pectate lyases (Lee et al. 2005), and it is likely that most of these proteins are secreted through the T2S. It is possible that $X$. oryzae pv. oryzae needs such a large number of hydrolytic enzymes in order to be able to degrade different plant cell wall components and their variously modified forms. Importantly, all cell-wall-degrading enzymes used in this study are effective at eliciting defense responses. Therefore, several other hydrolytic enzymes of $X$. oryzae pv. oryzae also might be effective at inducing host defense responses. As a consequence, mutations in one or a few T2S effectors may not significantly affect the induction of rice defense responses by a $\mathrm{T}^{3} \mathrm{~S}^{-}$mutant.

Our results indicate that infiltration of higher concentrations of either T2S effectors or the soluble elicitors released by their action on plant cell walls results in visible HR and lignin deposition. At lower concentrations, these effectors and elicitors induce callose deposition without either visible HR or lignin deposition. This suggests the possibility that a rice plant might be able to monitor the extent of damage to its cell wall, possibly by measuring the concentration of cell wall degradation products, and calibrate its response accordingly. Higher amounts of damage may result in the initiation of a cell death pathway, whereas lesser amounts of damage may result in the initiation of basal defense responses such as callose deposition.

Host recognition of pathogen-associated molecular pattern molecules such as lipopolysaccharides, flagellin, and so on may contribute to the residual defense responses that are induced in rice by the $\mathrm{T}_{2} \mathrm{~S}^{-} \mathrm{T} 3 \mathrm{~S}^{-}$double mutant of $X$. oryzae $\mathrm{pv}$. oryzae (Table 3 ). Plants recognize a number of pathogen-associated molecules and mount a defense response to evade infection, reflecting the adage that disease is an exception rather than the rule. These could be molecules like the bacterial flagellin (Zipfel et al. 2004), LPS (Newman et al. 2002), elongation factor Tu (Kunze et al. 2004; Zipfel et al. 2006), cold shock protein (Felix and Boller 2003), or plant cell-wall-degrading enzymes and cell wall degradation products (Darvill and Albersheim 1984; Ryan and Farmer 1991) or strain-specific molecules such as avirulence factors (Dangl and Jones 2001), which are recognized by cognate resistance $(R)$ gene products of the host. The model we propose suggests that a rice plant recognizes the cell-wall-degrading enzymes secreted via the $\mathrm{T} 2 \mathrm{~S}$ of $X$. oryzae pv. oryzae through cell wall degradation products generated by their activity, and triggers a resistance response to evade colonization by the pathogen. However, the bacterium now uses a T3S to overcome these defense responses. It further appears that, in plants, the defense response of the host to these signature molecules is most likely to be the first level of interaction and, in turn, the bacterium overcomes these responses by secreting T3S effectors. In a second level of interaction, the host has evolved $R$ genes whose products recognize T3S effectors or their effects (Axtell and Staskawicz 2003; Mackey et al. 2003), resulting in a more specific secondary defense response. Future work would be directed toward understanding the biochemical and signal transduction pathways that are involved in elaborating the defense responses induced by $\mathrm{T} 2 \mathrm{~S}$ effectors and identifying the T3S effectors that suppress them.

\section{MATERIALS AND METHODS}

\section{Bacterial strains, plasmids, and growth conditions.}

Bacterial strains, plasmids and primers used in this study are listed in Table 1. Media, growth conditions, and antibiotic markers for Escherichia coli and X. oryzae pv. oryzae have been described previously (Ray et al. 2000). Cellulase and Xylanase of Trichoderma spp. were obtained from Sigma-Aldrich (St. Louis). 
Construction of $\mathrm{T}^{-} \mathrm{S}^{-}$and $\mathrm{T}^{-} \mathrm{S}^{-} \mathrm{T}^{-} \mathrm{S}^{-}$double mutant $X$. oryzae pv. oryzae.

A 744-bp fragment of the $X$. oryzae pv. oryzae hrpB6 gene (a component of T3S apparatus; accession number AF026197) (Zhu et al. 2000) was PCR amplified using HrpB6F and HrpB6R oligonucleotide primers. This fragment was cloned into the pMOS-Blue blunt-ended cloning vector to obtain pGJ12. The plasmid pGJ12 then was electroporated into BXO43 electrocompetent cells to obtain the single recombinant ampicillin-resistant strain BXO2012 ( $h r p B 6^{-}$or $\mathrm{T}^{-} \mathrm{S}^{-}$mutant) by plasmid integration. PCR and sequencing of the PCR product were used to confirm that the gene disruption events had occurred as expected (data not shown). BXO2012 is deficient for virulence and lacks the ability to induce HR in the nonhost tomato plant. BXO802, an $\mathrm{Hrp}^{-}$derivative of $\mathrm{BXO} 43$, was obtained by ethylmethane sulfonate mutagenesis of $X$. oryzae pv. oryzae (Ray et al. 2000).

The previously isolated pSR1 plasmid (Ray et al. 2000) carrying a Tn 10 insertion in the $x p s F$ gene (which encodes a component of the $X$. oryzae pv. oryzae T2S) was mobilized from $E$. coli $\mathrm{S} 17-1$ into BXO2012 using biparental matings. A T2S $\mathrm{T}^{-} \mathrm{S}^{-}$double mutant (BXO2013) was generated by marker exchange of the xpsF::Tn10 insertion into the BXO2012 chromosome by screening for tetracycline-resistant, kanamycinsusceptible colonies. Tetracycline and kanamycin are the antibiotic resistance determinants encoded on the Tn 10 and pSR 1 plasmids, respectively. As expected, the BXO2013 strain was deficient for secretion of T2S effectors as determined by assaying secreted lipase and cellulase activities and extracellular protein profiles (data not shown).

\section{Purification and characterization of T2S effectors of $X$. oryzae pv. oryzae.}

T2S-secreted proteins were purified from culture supernatants of the wild-type BXO43 as described (Rajeshwari et al. 2005) with a slight modification, wherein the buffer used was $10 \mathrm{mM}$ potassium phosphate, $\mathrm{pH}$ 6.0. In order to identify the T2Ssecreted proteins that resolved as different peaks, MS/MS analysis was done following the protocol described (Rajeshwari et al. 2005). Cellulase (endoglucanase) activity of $X$. oryzae pv. oryzae strains was measured on PSA + CM-cellulose $(0.1 \%$ wt/vol) followed by staining with $1 \%$ Congo red and destaining with $1 \mathrm{M} \mathrm{NaCl}$ (Shoseyov and Doi 1990). A zone of clearing around the colonies was indicative of cellulase activity. The zone of clearing produced by the BXO43 strain had a radius of approximately $1.1 \mathrm{~cm}$, whereas the $c l s A^{-}$strain (BXO2002) did not produce any halo. Exoglucanase activity was measured using p-nitrophenyl cellobioside (Deshpande et al. 1988) and methyl umbelliferyl cellobioside (Shoseyov and Doi 1990) as substrates. Lipase assays were performed as described (Rajeshwari et al. 2005).

\section{Construction of mutants}

of $X$. oryzae pv. oryzae T2S-secreted proteins.

Partial gene fragments of $c l s A$ and $c b s A$ genes were PCR amplified from BXO43 genomic DNA with degenerate primers that were designed based on sequences of $X$. axonopodis pv. citri and X. campestris pv. campestris or Xylella fastidiosa homologues using the CODEHOP program (Rose et al. 1998). A 703-bp intragenic fragment of the $c l s A$ gene was PCR amplified using ClsF and ClsR primers and cloned into the pMOS-Blue blunt-end cloning vector (Amersham Pharmacia Biotech, Buckinghamshire, UK) to obtain pGJ2. Degenerate primers (Cbs F and CbsR) also were used to PCR amplify and sequence a 631-bp intragenic fragment of the $c b s A$ gene. Based upon the obtained sequence, specific primers $(\mathrm{sCbsF}$ and sCbsR) were made to PCR amplify a 520-bp fragment of the $c b s A$ gene and the product was cloned into the pMOS-Blue blunt-end cloning vector to obtain pGJ3. The $c b s A$ insert was released from pGJ3 by double digestion with PstI and BamHI and further cloned into similarly digested gentamycin-resistant vector pJQ200SK to obtain pGJ4. The plasmids pGJ2 and pGJ4 were isolated and recombined into the chromosome of BXO43 to obtain the single recombinant gene disruption Xanthomonas oryzae pv. oryzae mutants BXO2002 (for clsA) and BXO2003 (for $\operatorname{cbs} A$ ), respectively, by electroporation and selection for resistance to ampicillin and gentamycin, respectively. The previously cloned intragenic lipA gene fragment (Rajeshwari et al., 2005) was released from pGJ1 by double digestion with EcoRI and HindIII restriction enzymes and cloned into similarly digested kanamycin-resistant pET28b vector to obtain pGJ7. The pGJ7 was recombined into the chromosome of the BXO2002 strain by electroporation and selection for kanamycin resistance to obtain the clsA lipA double mutant (BXO2007). All of the gene disruption mutants obtained by electroporation were confirmed to be due to plasmid integration by PCR and sequencing of the PCR product (data not shown).

\section{Callose deposition assay.}

Rice leaves were infiltrated with either the saturated cultures (approximately $10^{9} \mathrm{CFU} / \mathrm{ml}$ ) of $X$. oryzae pv. oryzae strains (BXO2012, BXO2013, and BXO43) or diluted preparations ( 1 to $2 \mu \mathrm{g} / \mathrm{ml}$ ) of ClsA, CbsA, and LipA or supernatants of crude preparations of rice cell walls that had been treated with these enzymes. After 12 to $15 \mathrm{~h}$, the leaves were destained with lactophenol, stained with aniline blue for 2 to $3 \mathrm{~h}$, and analyzed by an Axioplan 2 epifluorescence microscope, using a blue filter (excitation wavelength $365 \mathrm{~nm}$ and emission wavelength above $420 \mathrm{~nm}$ long pass [LP]) and $\times 10$ objective (Hauck et al. 2003).

\section{HR assays.}

The adaxial surfaces of 10-day-old rice (susceptible cv. Taichung Native-1 [TN-1]) leaves were infiltrated individually with 30 to $40 \mu \mathrm{l}$ of purified ClsA, LipA, and CbsA (4 to $5 \mu \mathrm{g} / \mathrm{ml}$ each) with a $1-\mathrm{ml}$ hypodermic syringe without the needle, and HR-like symptoms (browning of infiltrated area) were observed 36 to $48 \mathrm{~h}$ after infiltration. Controls included only buffer, heat-inactivated enzymes, and the corresponding fraction from the respective $X$. oryzae pv. oryzae mutants (BXO2001 fraction for LipA and BXO2002 fraction for ClsA). Samples of leaf tissue (1 to $2 \mathrm{~cm}^{2}$ each) surrounding the infiltrated zone were cut and decolorized by boiling in lactophenol at $65^{\circ} \mathrm{C}$ for $30 \mathrm{~min}$, followed by boiling in $70 \%$ ethanol for $30 \mathrm{~min}$. These samples were mounted on microscope slides with $50 \%$ glycerol in $1 \times$ phosphate-buffered saline (PBS) and lignin-like autofluorescence was assessed by an Axioplan2 epifluorescence microscope (Carl Zeiss, Germany), using a green filter (excitation wavelength range 450 to $500 \mathrm{~nm}$ and detection range 515 to $565 \mathrm{~nm}$ ) and $\times 10 \mathrm{ob}-$ jective (Reimers and Leach 1991).

\section{Isolation of soluble elicitors.}

Crude cell wall preparations were isolated from leaves of 20-day-old TN-1 rice plants as described (York et al. 1985). In brief; leaves (10 g) were ground in liquid $\mathrm{N}_{2}$, successively washed with buffer $(10 \mathrm{mM}$ potassium phosphate buffer, $\mathrm{pH}$ 6.0), Milli-Q water, 1:1 chloroform/methanol, and acetone. The cell wall pellet was air dried on Whatman no. 1 filter paper after the acetone wash. Approximately 25 to $30 \mathrm{mg}$ of the isolated crude cell wall was treated with $500 \mu \mathrm{l}$ of each of the T2S effectors (4 to $5 \mu \mathrm{g} / \mathrm{ml}$ ) for $20 \mathrm{~h}$ at $37^{\circ} \mathrm{C}$ and spun down in a microfuge. The supernatants were collected, heat treated at 
$95^{\circ} \mathrm{C}$ for $1 \mathrm{~h}$ to inactivate the residual T2S enzyme activity, and immediately cooled by transferring to ice.

\section{Cell death assays.}

Rice (TN-1) seed were surface sterilized with sodium hypochlorite and germinated on $0.5 \%$ sterile agar in petri dishes for 3 to 4 days. Root tips, 1 to $2 \mathrm{~cm}$ long, were treated with each of the T2S-secreted effectors at 2 to $5 \mu \mathrm{g} / \mathrm{ml}$. After incubation for $16 \mathrm{~h}$, roots were washed in $1 \times$ PBS and stained with PI by vacuum infiltration for 10 to $15 \mathrm{~min}$. The roots were mounted on a microscopic slide in $50 \%$ glycerol in $1 \times \mathrm{PBS} ; 0.3-\mu \mathrm{m}$ thick longitudinal optical sections were acquired on a Zeiss LSM-510 Meta confocal microscope using $63 \times$ oil immersion (NA 1.4) and were further projected to obtain the image of 2to $3-\mu \mathrm{m}$ total thickness. An HeNe laser at $543 \mathrm{~nm}$ excitation and emission above $560 \mathrm{~nm}$ (LP) was used to detect PI internalization. All images were analyzed using LSM software and further edited using Photoshop (Adobe, San Jose, CA, U.S.A.). Controls included only buffer, heat-inactivated enzymes, and the corresponding FPLC fraction from the respective $X$. oryzae pv. oryzae mutants (BXO2001 fraction for LipA and BXO2002 fraction for ClsA).

\section{Preinoculation or coinoculation with $X$. oryzae pv. oryzae strains.}

Saturated cultures of $X$. oryzae pv. oryzae strains (BXO43, BXO2012, BXO802, and BXO2013) were grown in PS broth. The pellets were washed with the buffer $(10 \mathrm{mM}$ potassium phosphate buffer, $\mathrm{pH}$ 6.0) following centrifugation and redissolved in the same amount of the buffer. Roots (obtained as discussed above) were pretreated with $X$. oryzae pv. oryzae strains for $1 \mathrm{~h}$ at $28^{\circ} \mathrm{C}$. After rinsing with fresh buffer, they were treated with purified T2S effectors and processed further for confocal analysis as described above. Roots treated with $X$. oryzae pv. oryzae strains, without further treatment with enzymes, also were analyzed by confocal microscopy. For HR and lignin assays, the pelleted $X$. oryzae pv. oryzae strains were resuspended with the purified proteins (final concentration 4 to $5 \mu \mathrm{g} / \mathrm{ml}$ ) and infiltrated into the leaves as described above.

\section{Rice resistance assay.}

The midveins of leaves of approximately 30-day-old TN-1 rice seedlings were injected with 30 to $40 \mu \mathrm{l}$ of either purified ClsA, CbsA, or LipA (4 to $5 \mu \mathrm{g} / \mathrm{ml}$ ) or buffer alone, or saturated cultures of $\mathrm{BXO} 43, \mathrm{BXO} 2012$, or $\mathrm{BXO} 2013$ using a $1-\mathrm{ml}$ hypodermic syringe and needle. Between 20 and $24 \mathrm{~h}$ later, the BXO43 strain was inoculated onto the midvein, 2 to $3 \mathrm{~cm}$ below the point of initial injection, by pricking with a needle that had been used to touch a fresh bacterial colony. After 10 days, the leaves were observed for the appearance of visible disease lesions (discoloration of midvein and surrounding regions).

\section{Virulence assays.}

Wild-type and mutant strains of $X$. oryzae pv. oryzae were clip inoculated on leaves of approximately 40-day-old greenhouse-grown plants of the susceptible rice cv. TN-1 as described (Rajeshwari et al. 2005). Lesion lengths were measured 7 days after inoculation.

\section{ACKNOWLEDGMENTS}

G. Jha was supported by a fellowship from the Council of Scientific and Industrial Research (CSIR), Government of India. This work was supported, in part, by a grant to R. V. Sonti from the Department of Biotechnology, Government of India. We acknowledge the help of M. Sultana for primer synthesis, C. Subbalakshmi for running the FPLC, V. M. Dhople and C. Sundaram for MS-MS analysis, and R. Nandini for confocal analysis.

\section{LITERATURE CITED}

Abramovitch, R. B., Kim, Y.,J., Chen, S., Dickman, M. B., and Martin, G. B. 2003. Pseudomonas type III effector AvrPtoB induces plant disease susceptibility by inhibition of host programmed cell death. EMBO (Eur. Mol. Biol. Organ.) J. 22:60-69.

Abramovitch, R. B., and Martin, G. B. 2004. Strategies used by bacterial pathogens to suppress plant defenses. Curr. Opin. Plant Biol. 7:356364.

Alfano, J. R., and Collmer, A. 1997. The type III (Hrp) secretion pathway of plant pathogenic bacteria: trafficking Harpins, Avr proteins, and Death. J. Bacteriol. 179:5655-5662.

Axtell, M. J., and Staskawicz, B. J. 2003. Initiation of RPS2-specified disease resistance in Arabidopsis is coupled to the AvrRpt2-directed elimination of RIN4. Cell 112:369-377.

Bestwick, C. S., Bennett, M. H., and Mansfield, J. W. 1995. Hrp mutant of Pseudomonas syringae pv. phaseolicola induces cell wall alteration but not membrane damage leading to the hypersensitive reaction in lettuce. Plant Physiol. 108:503-516.

Braun, E. J., and Rodrigues, C. A. 1993. Purification and properties of an endoxylanase from a corn stalk rot strain of Erwinia chrysanthemi. Phytopathology 83:332-338.

Bretz, J. R., Mock, N. M., Charity, J. C., Zeyad, S., Baker, C. J., and Hutcheson, S. W. 2003. A translocated protein tyrosine phosphatase of Pseudomonas syringae pv. tomato DC3000 modulates plant defense response to infection. Mol. Microbiol. 49:389-400.

Brown, I., Mansfield, J., and Bonas, U. 1995. hrp Genes in Xanthomonas campestris pv. vesicatoria determine ability to suppress papilla deposition in pepper mesophyll cells. Mol. Plant-Microbe Interact. 8:825-836.

Chang, J. H., Goel, A. K., Grant, S. R., and Dangl, J. L. 2004. Wake of flood: ascribing functions to the wave of type III effector proteins of phytopathogenic bacteria. Curr. Opin. Microbiol. 7:11-18.

Dangl, J. L., and Jones, J. D. G. 2001. Plant pathogens and integrated defence responses to infection. Nature 411:826-833.

Darvill, A. G., and Albersheim, P. 1984. Phytoalexins and their elicitorsa defense against microbial infection in plants. Annu. Rev. Plant Physiol. 35:243-275.

da Silva, A. C., Ferro, J. A., Reinach, F. C., Farah, C. S., Furlan, L. R. Quaggio, R. B., Monteiro-Vitorello, C. B., Van Sluys, M. A., Almeida, N. F., Alves, L. M., do Amaral, A. M., Bertolini, M. C., Camargo, L. E., Camarotte, G., Cannavan, F., Cardozo, J., Chambergo, F., Ciapina, L. P., Cicarelli, R. M., Coutinho, L. L., Cursino-Santos, J. R., El-Dorry, H., Faria, J. B., Ferreira, A. J., Ferreira, R. C., Ferro, M. I., Formighieri, E. F., Franco, M. C., Greggio, C. C., Gruber, A., Katsuyama, A. M., Kishi, L. T., Leite, R. P., Lemos, E. G., Lemos, M. V., Locali, E. C., Machado, M. A., Madeira, A. M., Martinez-Rossi, N. M., Martins, E. C., Meidanis, J., Menck, C. F., Miyaki, C. Y., Moon, D. H., Moreira, L. M., Novo, M. T., Okura, V. K., Oliveira, M. C., Oliveira, V. R., Pereira, H. A., Rossi, A., Sena, J. A., Silva, C., de Souza, R. F., Spinola, L. A., Takita, M. A., Tamura, R. E., Teixeira, E. C., Tezza, R. I., Trindade dos Santos, M., Truffi, D., Tsai, S. M., White, F. F., Setubal, J. C., and Kitajima, J. P. 2002. Comparison of the genomes of two Xanthomonas pathogens with differing host specificities. Nature 417:459-463.

Deshpande, M. V., Pettersson, L. G., and Eriksson, K. E. 1988. Selective assay for exo-1,4- $\beta$-glucanases. Methods Enzymol. 160:126-130.

Esau, K. 1965. Plant anatomy. John Wiley and Sons, New York.

Espinosa, A., Guo, M., Tam, V. C., Fu, Z. Q., and Alfano, J. R. 2003. The Pseudomonas syringae type III-secreted protein HopPtoD2 possesses protein tyrosine phosphatase activity and suppresses programmed cell death in plants. Mol. Microbiol. 49:377-397.

Felix, G., and Boller, T. 2003. Molecular sensing of bacteria in plants. The highly conserved RNA-binding motif RNP-1 of bacterial cold shock proteins is recognized as an elicitor signal in tobacco. J. Biol. Chem. 278:6201-6208.

Felix, G., Duran, J. D., Volko, S., and Boller, T. 1999. Plants have a sensitive perception system for the most conserved domain of bacterial flagellin. Plant J. 18:265-276.

Goodman, R. N., and Novacky, A. J. 1994. The Hypersensitive Reaction in Plants to Pathogens. A Resistance Phenomenon. American Phytopathological Society Press, St. Paul, MN, U.S.A.

Hauck, P., Thilmony, R., and He, S. Y. 2003. A Pseudomonas syringe type III effector suppresses cell wall-based extracellular defense in susceptible Arabidopsis plants. Proc. Natl. Acad. Sci. U.S.A. 100:8577-8582.

Jacobek, J. L., and Lindgren, P. B. 1993. Generalized induction of defense responses in bean is not correlated with the induction of the hypersensitive reaction. Plant Cell 5:49-56.

Jamir, Y., Guo, M., Oh, H. S., Ocwieja, T. P., Chen, S., Tang, X., Dickman, M. B., Collmer, A., and Alfano, J. R. 2004. Identification of Pseudomonas syringae type III effectors that can suppress programmed cell death in plants and yeast. Plant J. 37:554-565. 
Jha, G., Rajeshwari, R., and Sonti, R. V. 2005. Bacterial type two secretion system secreted proteins: double-edged swords for plant pathogens. Mol. Plant Microbe Interact. 18:891-898.

Jones, D. A., and Takemoto, D. 2004. Plant innate immunity-direct and indirect recognition of general and specific pathogen-associated molecules. Curr. Opin. Immunol. 16:48-62.

Keshavarzi, M., Soylu, S., Brown, I., Bonas, U., Nicole, M., Rossiter, J., and Mansfield, J. 2004. Basal defenses induced in pepper by lipopolysaccharides are suppressed by Xanthomonas campestris pv. vesicatoria. Mol. Plant-Microbe Interact. 17:805-815.

Kim, M. G., Cunha, L. D., McFall, A. J., Belkhadir, Y., DebRoy, S., Dangl, J. L., and Mackey, D. 2005. Two Pseudomonas syringae type III effectors inhibit RIN4-regulated basal defense in Arabidopsis. Cell 121:749759.

Kunze, G., Zipfel, C., Robatzek, S., Niehaus, K., Boller, T., and Felix, G. 2004. The $\mathrm{N}$ terminus of bacterial elongation factor Tu elicits innate immunity in Arabidopsis plants. Plant Cell 16:3496-3507.

Lee, B. M., Park, Y. J., Park, D. S., Kang, H. W., Kim, J. G., Song, E. S. Park, I. C., Yoon, U. H., Hahn, J. H., Koo, B. S., Lee, G. B., Kim, H., Park, H. S., Yoon, K.O., Kim, J. H., Jung, C. H., Koh, N. H., Seo, J. S., and Go, S. J. 2005. The genome sequence of Xanthomonas oryzae pathovar oryzae KACC10331, the bacterial blight pathogen of rice. Nucleic Acids Res. 33:577-586.

Li, X., Lin, H., Zhang, W., Zou, Y., Zhang, J., Tang, X., and Zhou, J.-M. 2005. Flagellin induces innate immunity in nonhost interactions that is suppressed by Pseudomonas syringae effectors. Proc. Natl. Acad. Sci. U.S.A. 102:12990-12995.

Mackey, D., Belkhadir, Y., Alonso. J. M., Ecker, J. R., and Dangl, J. L. 2003. Arabidopsis RIN4 is a target of the type III virulence effector AvrRpt2 and modulates RPS2-mediated resistance. Cell 112:379-389.

McNeil, M., Darvill, A. G., Fry, S. C., and Albersheim, P. 1984. Structure and function of the primary-cell walls of plants. Annu. Rev. Biochem. 53:625-663.

Nomura, K., Melotto, M., and He, S.-Y. 2005. Suppression of host defense in compatible plant-Pseudomonas syringae interactions. Curr. Opin. Plant Biol. 8:361-368.

Newman, M.-A., Lahaye, E. R., Parr, A., Daniels M. J., and Dow, J. M. 2002. Prior exposure to lipopolysaccharide potentiates expression of plant defenses in response to bacteria. Plant J. 29:487-495.

Nurnberger, T., Brunner, F., Kemmerling, B., and Piater, L. 2004. Innate immunity in plants and animals: striking similarities and obvious differences. Immunol. Rev. 198:249-266.

Palva, T. K., Holmstrom, K.-O., Heino, P., and Palva, E. T. 1993. Induction of plant defense response by exoenzymes of Erwinia carotovora subsp. carotovora. Mol. Plant-Microbe Interact. 6:190-196.
Pennell, R. I., and Lamb, C. 1997. Programmed cell death in plants. Plant Cell 9:1157-1168.

Quandt, J., and Hynes, M. F. 1993. Versatile suicide vectors which allow direct selection for gene replacement in gram-negative bacteria. Gene 127:15-21.

Rajeshwari, R., Jha, G., and Sonti, R. V. 2005. Role of an in planta expressed xylanase of Xanthomonas oryzae pv. oryzae in promoting virulence on rice. Mol. Plant-Microbe Interact. 18:830-837.

Ray, S. K., Rajeshwari, R., and Sonti, R. V. 2000. Mutants of Xanthomonas oryzae pv. oryzae deficient in general secretary pathway are virulence deficient and unable to secrete xylanase. Mol. Plant-Microbe Interact. 13:394-401

Reimers, P. J., and Leach, J. E. 1991. Race-specific resistance to Xanthomonas oryzae pv. oryzae conferred by bacterial blight resistance gene $\mathrm{Xa-10}$ in rice (Oryza sativa) involves accumulation of a lignin-like substance in host tissues. Physiol. Mol. Plant Pathol. 38:39-55.

Ron, M., and Avni, A. 2004. The receptor for the fungal elicitor ethyleneinducing xylanase is a member of a resistance-like gene family in tomato. Plant Cell 10:1604-1615.

Rose, T. M., Schultz, E. R., Henikoff, J. G., Pietrokovski, S., McCallum C. M., and Henikoff, S. 1998. Consensus-degenerate hybrid oligonucleotide primers for amplification of distantly related sequences. Nucleic Acids Res. 26:1628-1635.

Ryan, C. A., and Farmer, E. E. 1991. Oligosaccharide signals in plants: A current assessment. Annu. Rev. Plant Physiol. Mol. Biol. 42:651-674.

Shoseyov, O., and Doi, R. H. 1990. Essential 170-kDa subunit for degradation of crystalline cellulose by Clostridium cellulovorans cellulase. Proc. Natl. Acad. Sci. U.S.A. 87:2192-2195.

Yang, B., Zhu, W., Johnson, L. B., and White, F. F. 2000. The virulence factor AvrXa7 of Xanthomonas oryzae pv. oryzae is a type III secretion pathway-dependent nuclear-localized double-stranded DNA binding protein. Proc. Natl. Acad. Sci. U.S.A. 97:9807-9812.

York, W. S., Darvill, A. G., McNeil, M., Stevenson, T. T., and Albersheim, P. 1985. Isolation and characterization of plant cell walls and cell wall components. Methods Enzymol. 118:3-40.

Zhu, W., MaGbanua, M. M., and White, F. F. 2000. Identification of two novel hrp associated genes in the hrp gene cluster of Xanthomonas oryzae pv. oryzae. J. Bacteriol. 182:1844-1853.

Zipfel, C., Kunze, G., Chinchilla, D., Caniard, A., Jones, J. D. G., Boller, T., and Felix. G. 2006. Perception of the bacterial PAMP EF-Tu by the receptor EFR restricts Agrobacterium-mediated transformation. Cell 125:749-760.

Zipfel, C., Robatzek, S., Navarro, L., Oakeley, E. J., Jones, J. D. G., Felix, G., and Boller, T. 2004. Bacterial disease resistance in Arabidopsis through flagellin perception. Nature 428:764-767. 